\title{
Metal-Free Catalyzed Ring-Opening Polymerization and Block Copolymerization of $\omega$-Pentadecalactone Using Amino-ended Initiators
}

\author{
E. Tinajero-Díaz, ${ }^{1}$ A. Martínez-de Ilarduya, ${ }^{1}$ S. Muñoz-Guerra, ${ }^{1 *}$ \\ M.-V. de-Paz, ${ }^{2}$ Elsa Galbis ${ }^{2}$ \\ ${ }^{1}$ Departament d’Enginyeria Química, Universitat Politècnica de Catalunya, ETSEIB, \\ Diagonal 647, 08028, Barcelona, Spain. \\ ${ }^{2}$ Departamento de Química Orgánica y Farmacéutica, Facultad de Farmacia, \\ Universidad de Sevilla, 41012, Sevilla, Spain.
}

\section{Abstract}

Metal-free catalysis was successfully applied to polymerize $\omega$-pentadecalactone (PDL) by ring-opening polymerization (ROP) using several amino-ended initiators, namely hexylamine, allylamine and $O, O^{\prime}$-bis(3-aminopropyl)diethylene glycol. This polymerization method was suitable to prepare telechelic polyesters carrying functional-end groups. The technique was then extended to the synthesis of block copolymers by ROP of PDL using bisamino-ended poly(ethylene glycol) $\left(M_{\mathrm{n}}=2600\right)$ as macroinitiator. $\mathrm{PPDL}_{\mathrm{x}}-\mathrm{PEG}_{56}-\mathrm{PPDL}_{\mathrm{x}}$ triblock copolymers with $M_{n}$ ranging between $\sim 4000$ and $\sim 90000 \mathrm{~g} \cdot \mathrm{mol}^{-1}$ were synthesized and extensively characterized by NMR, DSC, TGA and XRD. The amphiphilic copolymers thus produced were demonstrated to be able to self-assemble in nanoparticles with average diameters of $\sim 100-200 \mathrm{~nm}$ and morphologies highly depending on blocks lengths. The described synthetic route distinguishes in providing "clean" amphiphilic copolymers, which are attractive candidates for biomedical applications.

Keywords: macrolactones polymerization; amphiphilic block copolymers; enzymatic ringopening polymerization; polyethyleneglycol-polyester copolymers; amphiphilic block copolymer nanoparticles. 


\section{Introduction}

Aliphatic polyesters are biodegradable polymers with a great potential as materials to be used in temporary applications, particularly in biomedicine [1]. Macrolactones are easily accessible compounds that may be exploited for the production of polyesters by entropically-driven ring-opening polymerization (ROP) [2]. Polyesters from macrolactones are distinguished by displaying thermal and mechanical properties close to polyethylene while maintaining certain degree of biodegradability [3]. The interest for macrolactonesbased polyesters has largely increased in these last decades, not only because their singular properties but also due to the sustainability of newly appearing macrolactones that are synthesized from renewable resources [4].

The increasing demand for polymers free of metal-contaminants to be used as biomaterials has motivated that organic catalysts including enzymes are receiving great attention nowadays in the synthesis of polyesters [5]. In this regards, supported Candida antarctica Lipase B immobilized on Lewatit VP OC (CALB), commercialized as Novozyme 435 , has been used with great efficiency for the ROP of macrolactones, in particular for $\omega$ pentadecalactone (PDL) $[3,6]$ providing a synthetic route greener than the traditional ones based on the use of organometallic catalyst $[7,8]$. In addition, higher efficient processes of synthesis based on low-cost enzymes have been recently reported [9]. On the other hand, the use of organo-catalysts is another interesting approach that is gaining recognition in the synthesis of polyesters [10,11]. Thus (1,5,7-triazabicyclo[4.4.0]dec-5-ene), known as TBD, is a powerful nucleophile able to efficiently catalyze esterification reactions and that is widely recognized as an extremely active catalyst for the ROP of macrolactones $[11,12]$.

Nucleophiles are the common species initiating the ROP of lactones, and a good number of both medium- and large-size lactones have been successfully polymerized by this method using alcohols as initiators [13-16]. By contrast, the ROP of lactones initiated by amines has been scarcely explored in spite that their greater electron-releasing 
capability makes them particularly effective for such purpose. In fact, the information presently available for the ROP of lactones initiated by amino-ended compounds is scarce and limited almost exclusively to medium-size rings [17-21]. As far as we know, no papers reporting the homopolymerization or copolymerization of macrolactones initiated by amines, either primary or secondary, amino acids, peptides or amino-terminated oligomers, are found in the accessible literature. Nevertheless, polymerization of either strained lactones ( $\varepsilon$-caprolactone or lactides) or strainless lactones (large-ring size $>9$ ) initiated by primary amines could not differ appreciably from that initiated by alcohols. The use of amines as initiators will be then well justified when amino-ended compounds are desired to be jointed to the final polyesters, as it is for example the case of block copolymers made of polypeptides.

Telechelic polymers bearing end groups able to take part in polymerization reactions are interesting building blocks for the preparation of polymers with relatively complex chemical structures such as block copolymers and network polymers [22,23]. Poly(ethylene glycol) (PEG) and its derivatives are well-known hydrophilic polymers with a great presence in both chemical and biological fields. Amphiphilic copolymers based on telechelic PEG are on the focus of numerous investigations addressed to the development of copolymer designs spontaneously generated by self-assembly and suitable for applications as drug delivery systems (DDS) [24,25]. PEG copolymers exhibiting amphiphilic behavior are common and a good number of them are based on the ROP of medium-size lactones initiated by the hydroxyl-end groups of PEG [26-29]. On the contrary, only a few reports on the copolymerization of PEG with PDL have been published so far, and none dealing with amine-initiated ROP reactions. Recently Hadjichristidis et al., [16] have described PEG-b-PPDL diblock copolymers obtained by ROP of PDL initiated by PEG and catalyzed by phosphazene superbases but the properties of these copolymers were not examined. 
In this work, we exploit the advantages of organo-catalysts and enzymes to prepare telechelic polyesters using amino-ended compounds as initiators for the ROP of PDL. On the basis of these exploratory results, commercial bisamino-ended poly(ethylene glycol) $\left(\mathrm{NH}_{2}-\mathrm{PEG} \mathrm{G6}_{6}-\mathrm{NH}_{2}\right)$ was then used as a bisfunctional macroinitiator for the polymerization of PDL to render amphiphilic $P P D L_{x}-P E G_{56}-P P D L_{x}$ triblock copolymers avoiding the concourse of metallic compounds. These novel copolymers have been extensively characterized, their thermal properties evaluated, and their ability to form nanoparticles has been brought into evidence.

\section{Experimental part}

\subsection{Materials}

All chemicals, except otherwise stated, were purchased from Aldrich Chemical Co. Toluene was freshly distilled and kept on $3 \AA$ molecular sieves. Hexylamine (HexA), O,O'bis(3-aminopropyl)diethylene glycol (A-DEG-A), allyamine $\quad(A l l A), \quad 1,5,7-$ triazabicyclo[4.4.0]dec-5-ene (TBD) and bisamino-ended poly(ethylene glycol) (PEG) with $M_{n} \approx 2600$ were used as received. $\omega$-Pentadecalactone was freshly distilled in vacuum and stored under nitrogen. Novozym 435 (supported Candida antarctica Lipase B, CALB), a gift of Novozymes, and TBD were dried in a desiccator with $\mathrm{P}_{2} \mathrm{O}_{5}$ for $16 \mathrm{~h}$ at $50{ }^{0} \mathrm{C}$. Poly(vinyl alcohol) (PVA, $M_{W} \approx 3000,88 \%$ hydrolyzed) was obtained from Scientific Polymer Products, Inc. Solvents used for isolation and purification were of high-purity grade and used as received.

\subsection{General methods}

${ }^{1} \mathrm{H}$ and ${ }^{13} \mathrm{C}$ NMR spectra were recorded on a Bruker AMX-300 spectrometer at 25 ${ }^{0} \mathrm{C}$, operating at 300.1 and $75.5 \mathrm{MHz}$, respectively. Compounds were dissolved in deuterated chloroform $\left(\mathrm{CDCl}_{3}\right)$ and spectra were internally referenced to tetramethylsilane 
(TMS). About 10 and $50 \mathrm{mg}$ of sample in $1 \mathrm{~mL}$ of solvent were used for ${ }^{1} \mathrm{H}$ and ${ }^{13} \mathrm{C} \mathrm{NMR}$, respectively. Sixty-four scans were recorded for ${ }^{1} \mathrm{H}$, and between 1000 and 10000 scans for ${ }^{13} \mathrm{C}$ NMR. For $M_{n}$ determination the ${ }^{1} \mathrm{H}$ NMR methylene signal arising from $\mathrm{CH}_{2} \mathrm{OH}$ endgroups was compared to the $\mathrm{CH}_{2} \mathrm{OCO}$ signals for the case of PPDL homopolymers and to $\mathrm{CH}_{2} \mathrm{OCO}$ and $\mathrm{CH}_{2} \mathrm{CH}_{2} \mathrm{O}$ signals for the PPDL-PEG-PPDL copolymers initiated by bisamino ended PEG.

The thermal behavior of polymers was examined by differential scanning calorimetry (DSC) using a Perkin-Elmer Pyris apparatus. The thermograms were obtained from 4-6 mg samples at heating and cooling rates of $10^{\circ} \mathrm{C} \cdot \mathrm{min}^{-1}$ under a nitrogen flow of $20 \mathrm{~mL}$ $\min ^{-1}$. Indium and zinc were used as standards for temperature and enthalpy calibration. Thermogravimetric analysis was performed on a Mettler-Toledo TGA/DSC 1 Star System under a nitrogen flow of $20 \mathrm{~mL} \cdot \mathrm{min}^{-1}$ at a heating rate of $10{ }^{\circ} \mathrm{C} \cdot \mathrm{min}^{-1}$ and within a temperature range of $30-600{ }^{\circ} \mathrm{C}$.

Real time X-ray diffraction studies were carried out using X-ray synchrotron radiation at the BL11 beamline (non-crystalline diffraction (NCD)), at ALBA (Cerdanyola del Vallés, Barcelona, Spain). Spectra were recorded for powder samples subjected to heatingcooling cycles at rates of $10{ }^{\circ} \mathrm{C} \mathrm{min}{ }^{-1}$. The energy employed corresponded to a radiation of $0.10 \mathrm{~nm}$ wavelength, and spectra were calibrated with $\mathrm{Cr}_{2} \mathrm{O}_{3}$. Scanning electron microscopy images were taken with a field-emission JEOL JSM-7001F instrument or a Zeiss Auriga instrument operating at $5 \mathrm{kV}$ (CITIUS Service, University of Sevilla), from platinum/palladium coated samples from both platinum/palladium coated and uncoated samples. Dynamic light scattering (DLS) measurements used for particle hydrodynamic size and $\zeta$-potential determinations were performed with the Brookhaven NanoBrook, particle/protein size and zeta potential analyzer (Brookhaven Instruments Corporation, USA) with particles suspended in deionized water. 


\subsection{Synthesis of PPDL}

ROP of PDL was performed with the concourse of either enzymes or organic compounds as catalysts. For enzymatic polymerization, the amount of CALB was $20 \%$ $(w / w)$ with respect to monomer in all cases, and for chemo-catalyzed polymerization, different amounts of TBD were tested in order to reach high conversions of PDL. The general procedure was as follows: CALB or TBD was introduced in an open round-bottom flask provided with a magnetic stirrer which was placed in a desiccator at $50{ }^{\circ} \mathrm{C}$ for $16 \mathrm{~h}$. For CALB mediated polymerization, the amine used as initiator was dissolved in dry toluene $(5 \mathrm{~mL})$ and the solution poured into the reaction flask, which was then transferred to an oil-bath at $100^{\circ} \mathrm{C}$, and the calculated amount of PDL immediately added. When TBD was used, the required amounts of amine and PDL were added simultaneously to the catalyst, the flask was sealed, and the mixture was magnetically stirred at $100 \stackrel{\circ}{ } \mathrm{C}$ for the scheduled period of time. In both cases, aliquots were withdrawn at scheduled times and dissolved in $\mathrm{CDCl}_{3}$ to be subjected to ${ }^{1} \mathrm{H}$ NMR analysis in order to follow the reaction progress. As soon as conversion remained unchanged, the reaction was stopped by cooling. For removing the enzyme, the toluene was evaporated, the residue dispersed in chloroform, and CALB filtered off. The polymer was then precipitated by pouring the filtrate in cold methanol. For polymerizations catalyzed by TBD, the crude reaction mass was dissolved in chloroform and precipitated in cold methanol. Irrespective of the catalyst used, the polymer was recovered by filtration and dried at room temperature under vacuum before characterization.

\subsection{Synthesis of PPDL-PEG-PPDL triblock copolymers}

For the reactions carried out by enzymatic catalysis, the amount of CALB used was $20 \%(\mathrm{w} / \mathrm{w})$ respect to monomer. For polymerizations catalyzed by TBD, the amount of catalyst added was previously optimized to attain the highest conversion of PDL. The 
general procedure was as follows: CALB or TBD was introduced in a round-bottom flask provided with a magnetic stirrer which was then placed in a desiccator at $50{ }^{\circ} \mathrm{C}$ for $16 \mathrm{~h}$. When CALB was used, a solution of PEG $\left(M_{n} \approx 2,600\right)$ in dry toluene was added to the flask, which was transferred to an oil-bath at $100^{\circ} \mathrm{C}$. Then, PDL was added and the solution magnetically stirred for at least $4 \mathrm{~h}$. When TBD was the catalyst of choice, the required amounts of PEG and PDL were added into the flask, which was then sealed and heated at $100{ }^{\circ} \mathrm{C}$ under magnetic stirring for $12 \mathrm{~h}$. In all cases aliquots of the reaction mixture were withdrawn and analyzed by ${ }^{1} \mathrm{H}$ NMR in order to assess the advance of the polymerization reaction. For removing CALB, the toluene was evaporated under vacuum, the residue was re-dissolved in an excess of chloroform, and the enzyme was removed by filtration. The filtrate was then concentrated and precipitated in an excess of cold methanol. For polymerizations using TBD, the crude reaction mass was dissolved in chloroform and the solution precipitated in an excess of methanol. Regardless of the catalyst chosen, the copolymer was collected by filtration and dried in vacuum before characterization.

\subsection{Preparation of nanoparticles}

Nanoparticles were prepared by the oil-in-water single emulsion technique with minor modifications. Specifically, $10 \mathrm{mg}$ of $P P D L_{x} P E G_{56} P P D L_{x}$ copolymer were dissolved in $2 \mathrm{~mL}$ of methylene chloride and the solution added to $10 \mathrm{~mL}$ of $5 \%(\mathrm{w} / \mathrm{w})$ PVA aqueous solution. The mixture was sonicated for $15 \mathrm{~s}$ three times to yield a homogeneous oil-inwater emulsion. This emulsion was immediately poured into $10 \mathrm{~mL}$ of the $0.3 \%$ PVA solution, and the mixture was magnetically stirred in an open beaker at room temperature for 3 h. Nanoparticles were formed along with the gradual evaporation of methylene chloride. The nanoparticles were collected by centrifugation at $11000 \mathrm{~g}$ for $15 \mathrm{~min}$ and washed three times with distilled water. 


\section{Results and discussion}

\subsection{ROP of $\omega$-pentadecalactone}

The route used for the synthesis of PPDL and PPDL ${ }_{x} P E G_{56} P P D L_{x}$ using CALB or TBD catalysts is depicted in Scheme 1, and results obtained in the homopolymerization of PDL under different conditions are compared In Table 1.

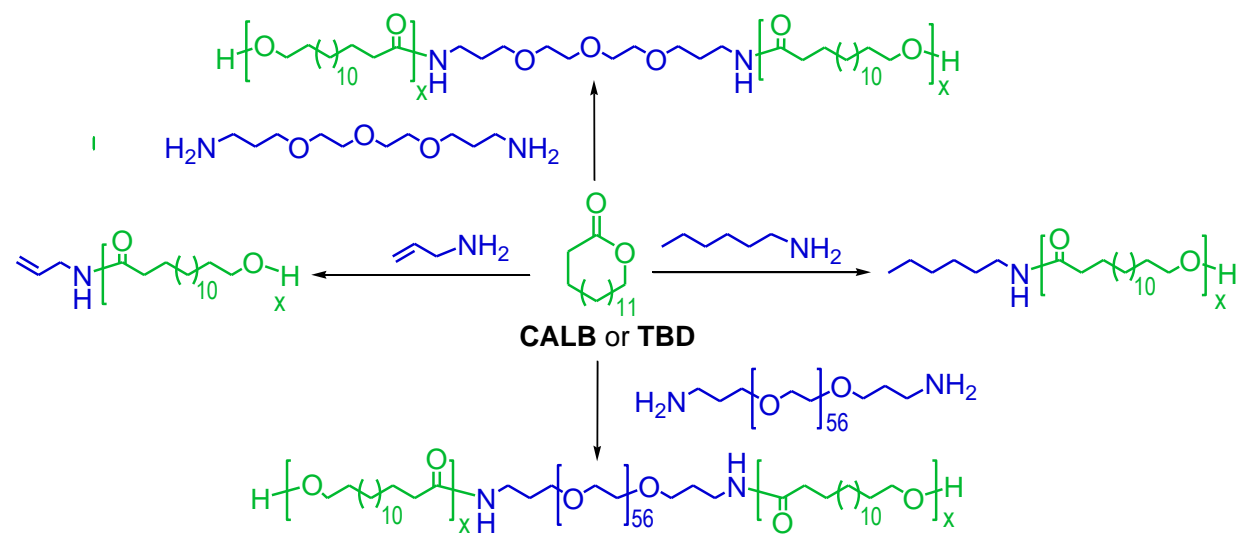

Scheme 1. ROP of $\omega$-pentadecalactone with either CALB or TBD as catalyst and amino-ended compounds as initiators

Table 1. ROP of $\omega$-pentadecalactone (PDL) initiated by amines and catalyzed by either TBD or CALB.

\begin{tabular}{|c|c|c|c|c|c|c|}
\hline Entry & Initiator $^{\mathrm{a}}$ & {$[\mathrm{PDL}]_{0} /[\mathrm{Cat}]_{0} /[\mathrm{Ini}]_{0}^{\mathrm{b}}$} & $\begin{array}{l}\text { Time } \\
\text { (h) }\end{array}$ & $\begin{array}{c}\text { Conversion } \\
\text { (\%) }\end{array}$ & $\begin{array}{l}\text { Yield } \\
(\%)\end{array}$ & $\begin{array}{c}M \mathrm{n}^{\mathrm{d}} \\
\left(\mathrm{g} \cdot \mathrm{mol}^{-1}\right)\end{array}$ \\
\hline \multicolumn{7}{|l|}{ TBD } \\
\hline 1 & - & $100 / 5 / 0$ & 12 & - & - & - \\
\hline 2 & HexA & $100 / 1 / 1$ & 96 & 40 & 24 & 5300 \\
\hline 3 & HexA & $100 / 10 / 10$ & 96 & 64 & 37 & 2100 \\
\hline 4 & A-DEG-A & $100 / 1 / 1$ & 72 & 40 & 22 & 9000 \\
\hline 5 & A-DEG-A & $100 / 5 / 1$ & 12 & 99 & 87 & 19700 \\
\hline \multicolumn{7}{|l|}{ CALB } \\
\hline 6 & HexA & $100 / 5$ & 3 & 99 & 97 & 5500 \\
\hline 7 & A-DEG-A & $100 / 10$ & 3 & 99 & 95 & 5300 \\
\hline 8 & AllA & $100 / 5$ & 3 & 99 & 93 & 5000 \\
\hline 9 & AllA & $100 / 10$ & 3 & 96 & 83 & 3400 \\
\hline
\end{tabular}

a HexA: hexylamine; A-DEG-A: O,O'-bis(3-aminopropyl)diethylene glycol; AllA: allylamine.

${ }^{b}$ Molar ratio in the feed. For enzymatic reactions the amount of CALB was $20 \%(w / w)$ respect to PDL.

${ }^{c}$ Conversion of PDL at the indicated reaction time as determined by ${ }^{1} \mathrm{H}$ NMR.

${ }^{\mathrm{d}}$ Number-average molecular weight of the resulting PPDL determined by ${ }^{1} \mathrm{H}$ NMR. 
The ${ }^{1} \mathrm{H}$ NMR spectra of the PPDL obtained by ROP catalyzed by CALB and initiated by the three amino-ended nucleophiles under study (entries 6, 7 and 8) are shown in Fig. 1. These amines acted as initiators in the polymerization of PDL and remained therefore incorporated in the growing polymer chain [30]. In every case a signal appeared at 2.15 ppm which is indicative of the presence of the amide group generated by the nucleophilic attack of the amine to the carboxylate group of PDL with subsequent ring opening and polymerization initiation. Additional signals could be detected at $3.37 \mathrm{ppm}$ and $3.25 \mathrm{ppm}$ when HexA and A-DEG-A were used as initiators (signal a in spectra $A$ and $B$, respectively). Such quadruplet signals arise from the $\alpha$-methylene protons of the amide group and their presence confirmed the incorporation of the amino-compounds into the polymer chain. Conversely, this signal appeared at $3.9 \mathrm{ppm}$ in the spectrum of the PDDL initiated by AllA (signal a in spectrum $C$ ) as a consequence of the deshielding effect provoked by the presence of the adjacent double bond. On the other hand, characteristic signals arising from the polyester are shared by PPDL regardless the nucleophile used. Triplets at 3.64 ppm and 4.05 ppm corresponding to protons of ended-chain $\mathrm{C}_{2} \mathrm{OH}$ and $\mathrm{COOC}_{2}$, respectively, were present in all spectra. A quantification of the areas of these signals allowed estimating the number-average molecular weights of the resulting PPDL, which varied between $\sim 2000$ and $\sim 20000 \mathrm{~g} \cdot \mathrm{mol}^{-1}$ showing a large dependence on the reaction conditions used. A comparison of the conversion, yield and $M_{\mathrm{n}}$ values given in Table 1 led to conclude the following: a) ROP of PDL was not feasible in the absence of initiator (entry 1), b) the influence of initiator on results was small as far as CALB was used as catalyst (entries 6-9), and c) the best results were attained in the ROP initiated by 1 mol-\% DEG and catalyzed by 5 mol-\% TBD relative to the amount of used monomer (entry 5).

It should be remarked that ROP of the macrolactone took place almost exclusively by amine initiation ROP of PDL as it is demonstrated by measuring the $\mathrm{CH}_{2} \mathrm{OH}$ and 
$\mathrm{CH}_{2} \mathrm{NCO}$ signals areas of the formed polyesters. ${ }^{1} \mathrm{H}-\mathrm{NMR}$ spectra of AllA-PPDL before and after purification (Table 1, entry 8 ) with these signals enlarged for a reliable comparison are shown in Fig. S1 of the Electronic Supporting Information file (ESI). On the other hand it can be stated that the low yields attained for entries 2, 3 and 4 are due to the lack of reactivity of the macrolactone under the conditions used in such cases. The ${ }^{1} \mathrm{H}-\mathrm{NMR}$ spectrum of the reaction product of the polymerization initiated by hexylamine before purification (Table 1, entry 2) is shown in Fig. S2 of the ESI file.

A preliminary thermal characterization of PPDLs obtained by amine-initiated ROP was carried out by TGA and DSC. TGA thermograms of PPDLs synthesized using each different nucleophile are compared in Fig. 2a. The thermal decomposition process started above $300^{\circ} \mathrm{C}$ and happened in one step with the maximum decomposition rate at $\sim 425 \stackrel{\circ}{\circ}$ regardless the initiator used. Essentially the same behavior was observed for the three cases with small differences being within the limits of experimental errors. Fig. $2 \mathrm{~b}$ displays the DSC traces of the amino-initiated PPDLs. The thermograms recorded at both cooling and heating are extremely similar showing in the three case sharp crystallization and melting peaks at temperatures around $75^{\circ} \mathrm{C}$ and $90^{\circ} \mathrm{C}$, respectively. 

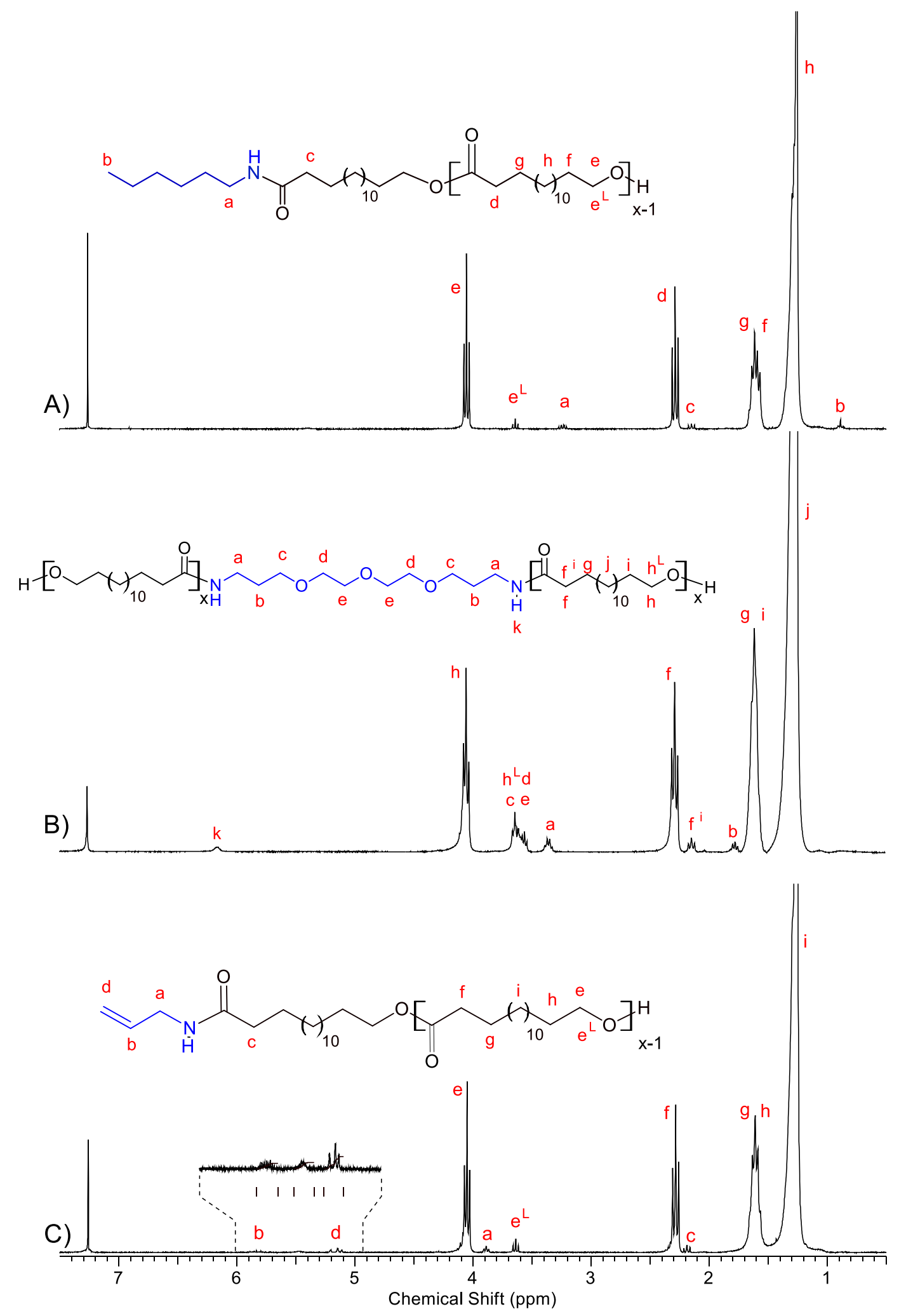

Fig.1. ${ }^{1} \mathrm{H}$ NMR $\left(\mathrm{CDCl}_{3}\right)$ spectra of PPDL prepared by ROP initiated by A) HexA, B) A-DEG-A, and C) AllA. Superscripts I and $L$ refer to signals arising from the first and last repeating units of the polyester chain, respectively. 

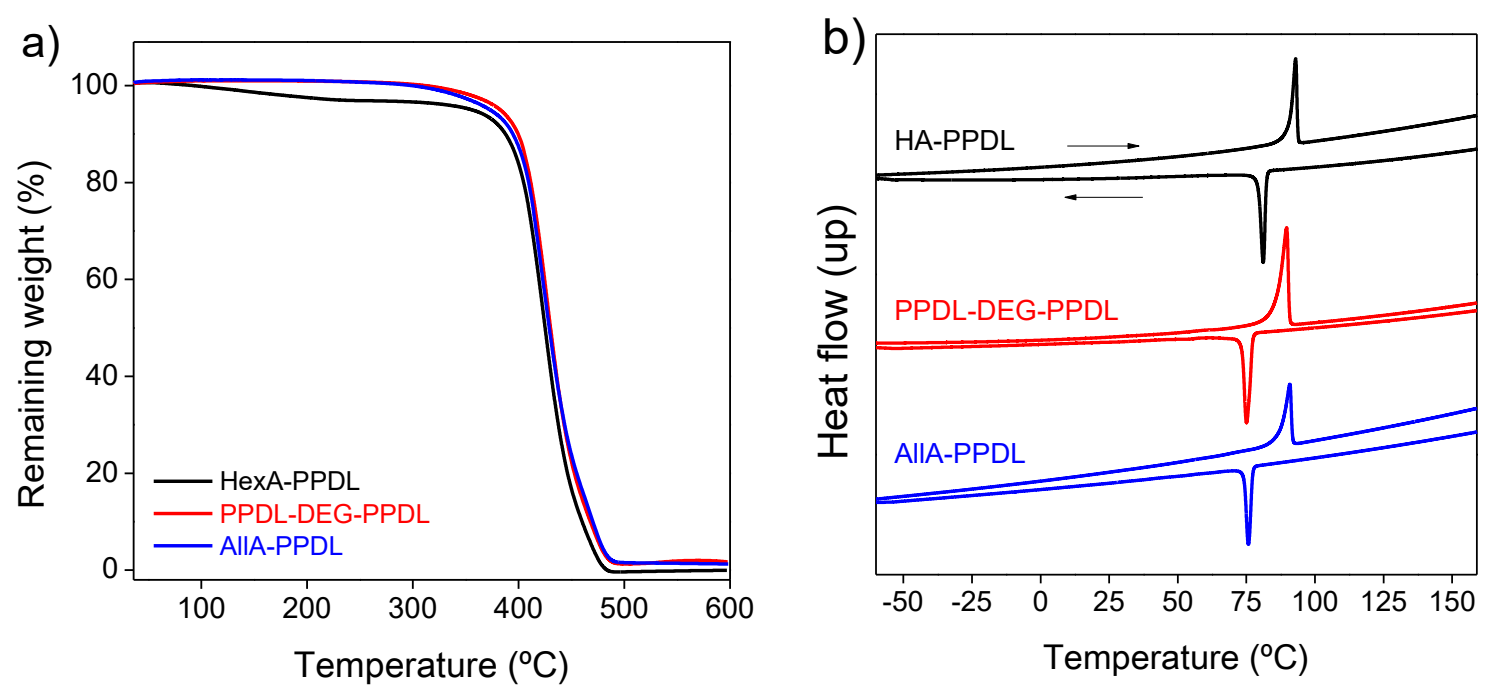

Fig.2. Thermal analysis of amine-initiated PPDLs. a) TGA traces recorded under an inert atmosphere. b) DSC traces registered at cooling and reheating from samples previously heated at $200 \stackrel{\circ}{-C}$.

\subsection{Synthesis $P P D L_{x} P E G_{y} P P D L_{x}$ triblock copolymers}

The promising results obtained in the ROP of PDL initiated by amino compounds encouraged us to carry out the synthesis of amphiphilic triblock copolymers by using diamine-ended PEG as double initiator for generating the PPDL blocks from PDL (Scheme 1). The PEG of choice was a sample with number-average polymerization degree of 56 (corresponding to a $M_{n}$ of approximately $2700 \mathrm{~g} \cdot \mathrm{mol}^{-1}$ ) and both organo-chemical (TBD) and enzymatic (CALB) catalysts were used. All reactions were conducted in bulk at a temperature of $100^{\circ} \mathrm{C}$. Copolymerizations with PEG:PDL molar ratios in the feed ranging between 1:25 and 1:42, which correspond to EG:PDL ratios of 2 to 0.13 , were performed. Reaction conditions and results obtained for every case are collected in Table 2. Acceptable yield values were attained in all cases (>70\%) and according to the copolymer compositions, loses of product are due to incomplete reaction of PDL. Such a defect in the reactivity of the macrolactone was more pronounced when the polymerization was catalyzed by TBD. 
The chemical constitution and block composition of the copolymers were ascertained by NMR. ${ }^{1} \mathrm{H}$ and ${ }^{13} \mathrm{C}$ NMR spectra of $\mathrm{PPDL}_{46} \mathrm{PEG}_{56} \mathrm{PPDL}_{46}$ (entry 5 of Table 2) are depicted in Fig. 3. ${ }^{1} \mathrm{H}$ NMR spectra of the all other copolymers are given in Fig. S3 of ESI. Insets containing enlarged regions have been inserted to show details difficult to observe in the straight representations. Signals arising from methylenes of the first and last pentadecanoate units as well as those due to the protons contained in the 3oxyaminopropylene units of the central PEG block are made visible in the insets and used to determine the molecular weight of the copolymers. The $M_{n}$ values obtained by this analysis are given in Table 2 and found to be consistent with the block lengths calculated by area quantification of signals specifically arising from PEG and PPDL blocks. It should be noticed that no signals arising from the aminopropyl groups of the bisamino-ended PEG used as macroinitiator were detected in the ${ }^{1} \mathrm{H}$ NMR spectra of the reaction product before purification, which is taken as indicative that all amine groups were active at initiating ROP of PDL (Fig. S4).On the other hand, the absence of homopolyester PPDL was ascertained by comparing ${ }^{1} \mathrm{H}$ NMR signals arising from end $\mathrm{C}_{2} \underline{O} \mathrm{OH}, \mathrm{HNCOC} \underline{H}_{2}$ and $\mathrm{C}_{2} \underline{2}$, which gave the same number of protons for the all three (Fig. S5). Similar results were obtained for the analysis of PPDL prepared by short amine initiation (Fig. S6). 
Table 2. Reaction conditions and results of the synthesis of $P P D L_{x} P E G_{56} P P D L_{x}$ triblock copolymers. $^{\text {a }}$

\begin{tabular}{|c|c|c|c|c|c|c|}
\hline \multirow[t]{2}{*}{ Entry } & \multirow[t]{2}{*}{ Copolymer $^{b}$} & \multirow{2}{*}{$\begin{array}{l}\text { Time } \\
\text { (h) }\end{array}$} & \multirow{2}{*}{$\begin{array}{l}\text { Yield } \\
(\%)\end{array}$} & \multicolumn{2}{|c|}{$[\mathrm{PEG}] /[\mathrm{PDL}]^{\mathrm{C}}$} & \multirow{2}{*}{$\begin{array}{c}M_{n}{ }^{\mathrm{d}} \\
\left(\mathrm{g} \cdot \mathrm{mol}^{-1}\right)\end{array}$} \\
\hline & & & & Feed & Copolymer & \\
\hline \multicolumn{7}{|c|}{ Organic catalysis (TBD) $^{e}$} \\
\hline 1 & $\mathrm{PPDL}_{12} \mathrm{PEG}_{56} \mathrm{PPDL}_{12}$ & 3 & 87 & $1 / 25$ & $1 / 23$ & 8300 \\
\hline 2 & $\mathrm{PPDL}_{34} \mathrm{PEG}_{56} \mathrm{PPDL}_{34}$ & 3 & 71 & $1 / 100$ & $1 / 68$ & 18700 \\
\hline 3 & $\mathrm{PPDL}_{65} \mathrm{PEG}_{56} \mathrm{PPDL}_{65}$ & 12 & 70 & $1 / 200$ & $1 / 131$ & 33600 \\
\hline \multicolumn{7}{|c|}{ Enzymatic catalysis (CALB) ${ }^{f}$} \\
\hline 4 & $\mathrm{PPDL}_{16} \mathrm{PEG}_{56} \mathrm{PPDL}_{16}$ & 3 & 92 & $1 / 35$ & $1 / 32$ & 10650 \\
\hline 5 & $\mathrm{PPDL}_{47} \mathrm{PEG}_{56} \mathrm{PPDL}_{47}$ & 12 & 94 & $1 / 100$ & $1 / 94$ & 25600 \\
\hline 6 & $\mathrm{PPDL}_{191} \mathrm{PEG}_{56} \mathrm{PPDL}_{191}$ & 12 & 85 & $1 / 420$ & $1 / 392$ & 94600 \\
\hline
\end{tabular}

${ }^{\mathrm{a}}$ All reactions performed at $100{ }^{\circ} \mathrm{C}$ in bulk.

${ }^{b}$ Obtained copolymers with the indicated block lengths as determined from their compositions.

${ }^{c}$ Molar PEG:PDL ratio in the feed and in the copolymer as determined by ${ }^{1} \mathrm{H}$ NMR analysis.

${ }^{\mathrm{d}}$ Number-average molecular weight determined by ${ }^{1} \mathrm{H}$ NMR analysis of end-groups.

${ }^{\text {e }}$ Reactions catalyzed by $5 \%$-mol of TBT.

${ }^{f}$ Reactions catalyzed by $20 \%(\mathrm{w} / \mathrm{w})$ of CALB. 

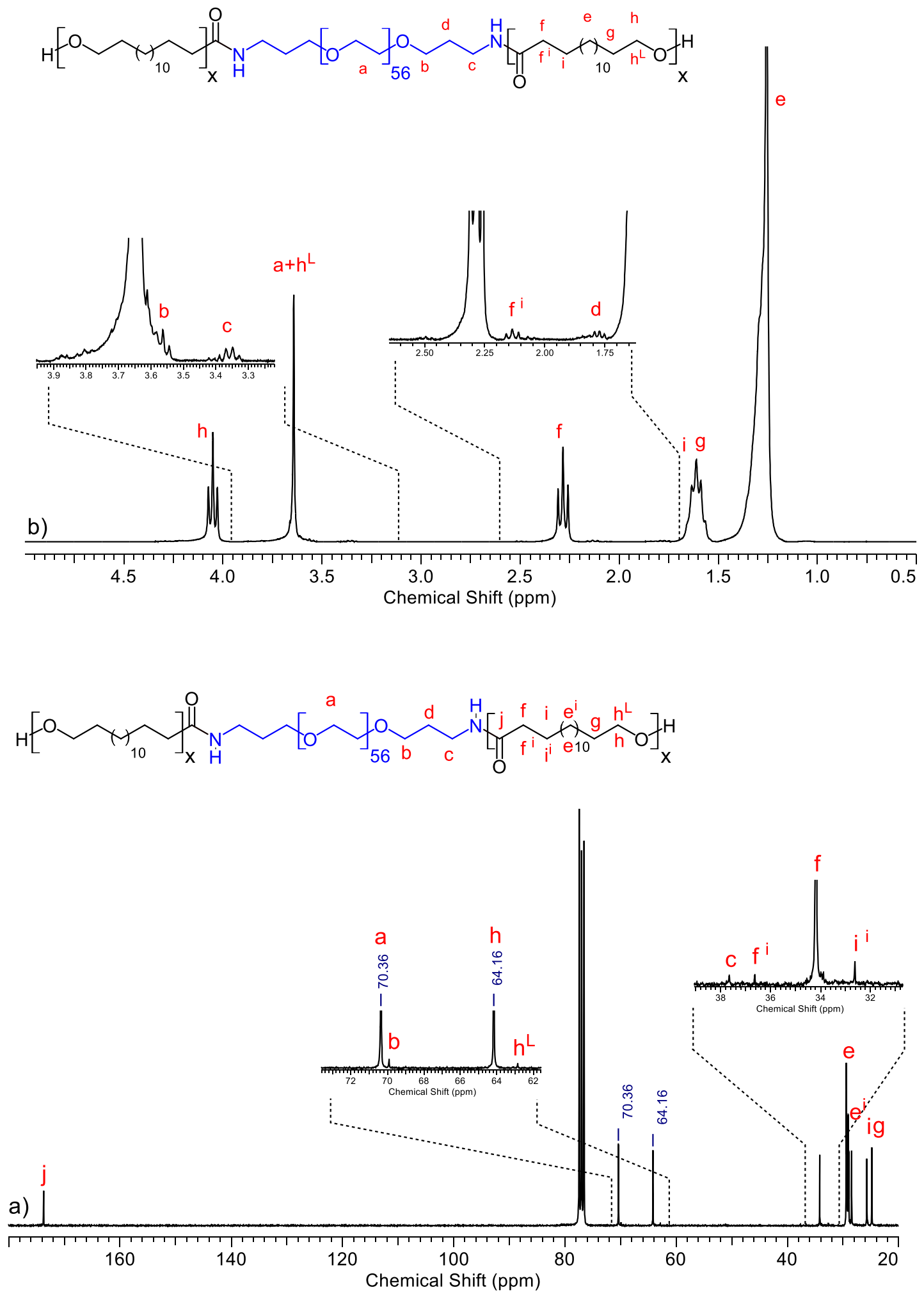

Fig. 3. ${ }^{13} \mathrm{C}$ NMR (a) and ${ }^{1} \mathrm{H}$ NMR (b) spectra of $\mathrm{PPDL}_{46} \mathrm{PEG}_{56} \mathrm{PPDL}_{46}$ (entry 5, Table 2). Superscripts $I$ and $L$ refer to signals arising from the first and last repeating units of the polyester chain, respectively. 


\subsection{Thermal properties of PPDL ${ }_{x} P G_{56} P_{P D L}$ triblock copolymers}

The triblock copolymers synthesized by the two procedures were comparatively examined by TGA and DSC with the purpose of assessing their thermal behavior as a function of both the length of the PPDL blocks and the method used for their synthesis. The thermal parameters obtained from these assays are collected in Table 3. The TGA traces recorded from the copolymers and the two homopolymers as well as their derivative curves are shown in Fig. 4.

Table 3. Thermal properties and crystallizability of $P P D L_{x} P E G_{56} P P D L_{x}$ triblock copolymers.

\begin{tabular}{|c|c|c|c|c|c|c|c|c|c|c|c|}
\hline \multirow{3}{*}{ Copolymer } & & & & \multicolumn{8}{|c|}{$\mathrm{DSC}^{\mathrm{D}}$} \\
\hline & \multicolumn{3}{|c|}{$T G A^{a}$} & \multicolumn{3}{|c|}{ Heating } & \multicolumn{2}{|c|}{ Cooling } & \multicolumn{3}{|c|}{$\begin{array}{l}\text { Crystallization } \\
\text { kinetics }^{\circ}\end{array}$} \\
\hline & $\begin{array}{l}{ }^{\circ} T_{d} \\
{ }^{\circ} \mathrm{C}\end{array}$ & $\begin{array}{l}{ }^{\max } T_{d} \\
{ }^{\circ} \mathrm{C}\end{array}$ & $\begin{array}{l}R_{w} \\
\%\end{array}$ & $\begin{array}{l}{ }^{1} T_{m}{ }^{1} \Delta H_{m} \\
{ }^{\circ} \mathrm{C} J \cdot \mathrm{g}^{-1}\end{array}$ & $\begin{array}{l}{ }^{2} T_{m} \\
{ }^{\circ} \mathrm{C}\end{array}$ & $\begin{array}{l}{ }^{2} \Delta H_{m} \\
\mathrm{~J} \cdot \mathrm{g}^{-1}\end{array}$ & $\begin{array}{l}T_{c} \\
\stackrel{\circ}{\circ} \mathrm{C}\end{array}$ & $\begin{array}{l}\Delta H_{c} \\
\mathrm{~J} \cdot \mathrm{g}^{-1}\end{array}$ & $n$ & $\ln K$ & $\begin{array}{c}t_{1 / 2} \\
\mathrm{~s}\end{array}$ \\
\hline \multicolumn{12}{|l|}{$\begin{array}{l}\text { Organic catalysis } \\
\text { (TBD) }\end{array}$} \\
\hline $\mathrm{PPDL}_{12} \mathrm{PEG}_{56} \mathrm{PPDL}_{12}$ & 385 & 427,470 & 2 & 90121 & 77 & 121 & 77 & -110 & 2.1 & -1.4 & 1.7 \\
\hline $\mathrm{PPDL}_{33} \mathrm{PEG}_{56} \mathrm{PPDL}_{33}$ & 381 & 424,470 & 2 & 95135 & 89 & 138 & 81 & -117 & 2.0 & -1.4 & 1.7 \\
\hline $\mathrm{PPDL}_{65} \mathrm{PEG}_{56} \mathrm{PPDL}_{65}$ & 399 & 424,472 & 4 & 95143 & 90 & 150 & 81 & -123 & 1.9 & -1.1 & 1.5 \\
\hline \multicolumn{12}{|l|}{$\begin{array}{l}\text { Enzymatic catalysis } \\
\text { (CALB) }\end{array}$} \\
\hline $\mathrm{PPDL}_{16} \mathrm{PEG}_{56} \mathrm{PPDL}_{16}$ & 394 & 423,472 & 1 & 92122 & 84 & 102 & 77 & -111 & 1.7 & -2.2 & 2.7 \\
\hline $\mathrm{PPDL}_{46} \mathrm{PEG}_{56} \mathrm{PPDL}_{46}$ & 394 & 422,472 & 1 & 94132 & 88 & 110 & 79 & -115 & 1.9 & -2.3 & 2.7 \\
\hline $\mathrm{PPDL}_{191} \mathrm{PEG}_{56} \mathrm{PPDL}_{191}$ & 383 & 421,472 & 6 & 95180 & 90 & 160 & 81 & -162 & 2.1 & -2.5 & 2.8 \\
\hline PEG & 373 & 406,472 & 2 & 59169 & 56 & 148 & 20 & -136 & & & \\
\hline PPDL & 399 & 423,470 & 2 & 93150 & 91 & 143 & 75 & -119 & 1.4 & -4.3 & 9.6 \\
\hline
\end{tabular}

${ }^{\mathrm{a}}$ Onset for $10 \%$ weight loss $\left({ }^{\circ} T_{d}\right)$ and maximum rate $\left({ }^{\max } T_{d}\right)$ thermal decomposition temperatures measured in the TGA analysis performed under inert atmosphere. $R_{w}$ : weight (\%) remaining after heating at $600 \stackrel{\circ}{\circ}$.

${ }^{b}$ Melting $\left(T_{m}\right.$ and $\left.\Delta H_{m}\right)$ and crystallization $\left(T_{c}\right.$ and $\left.\Delta H_{c}\right)$ temperatures and enthalpies measured by DSC. 1 and 2 superscripts refer to the first and second heating runs.

${ }^{c}$ Avrami parameters for the isothermal crystallization taking place at $84 \stackrel{\circ}{\circ}$.

The high thermal stability of PEG and PPDL homopolymers is a well-known fact $[3,31]$. Both compounds start to undergone perceivable decomposition well above $350 \stackrel{\circ}{ } \mathrm{C}$ 
and their decomposition in bulk happens in two stages at temperatures between $400{ }^{\circ} \mathrm{C}$ and $500^{\circ} \mathrm{C}$ leaving insignificant amounts of remaining weight. As it is shown in Table 3 ,
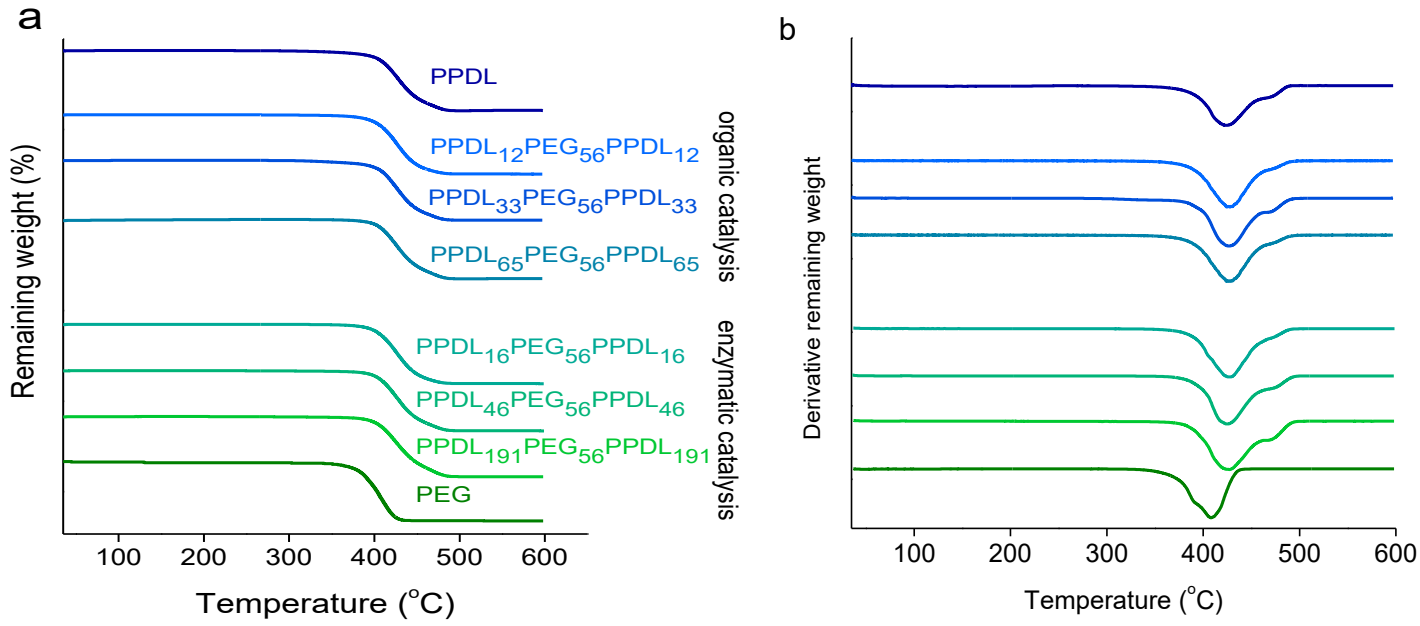

Fig. 4. a) $T G A$ traces registered under inert atmosphere of $P P D L_{x} P E G_{56} P P D L_{x}$ copolymers and b) their derivative curves.

the thermal stability of the PPDL ${ }_{x} P E G_{56} P P D L_{x}$ triblock copolymers is fully consistent with the behavior observed for the homopolymers. ${ }^{\circ} T_{d}$ of copolymers are in the $380-400{ }^{\circ} \mathrm{C}$ range and their ${ }^{\max } T_{d}$ are about $420-425{ }^{\circ} \mathrm{C}$ and $470-472{ }^{\circ} \mathrm{C}$ for the first and second decomposition steps, respectively. Although differences in the decomposition temperatures of the copolymers are small and practically negligible when the two series are compared, it is noticed that onset temperatures are slightly higher for the copolymers prepared by enzymatic ROP, and that in general all decomposition temperatures are closer to those of PPDL. The first observation is rather reasonable since the catalyst remaining in the copolyesters is expected to enhance the starting decomposition of the polymer. On the contrary, the stronger influence of the PDL blocks on the thermal stability of the copolymers compare to the EG blocks is not readily explainable and a more detailed study of the decomposition mechanism is needed to account for such difference. 
The DSC study carried out on the PPDL ${ }_{x} \mathrm{PEG}_{56} \mathrm{PPDL}_{x}$ copolymers included the analysis of the melting-crystallization process taking place at heating, cooling and reheating. Traces registered for the two copolymers series are compared in Fig. 5 and the $T_{m}$ and $T_{c}$ values observed for each one of them together with their associated enthalpies are listed in Table 3. Apparently, the PDL's block is crystallized in all copolymers whichever is the composition. "As synthesized" samples melted in the 90-95 ${ }^{\circ} \mathrm{C}$ with values showing no significant differences between the two series but slightly increasing in each of them with the length of the polyester block. Also the melting enthalpies measured for the copolymers increased monotonically with the content in PDL as expected, but it was striking to observe that values are greater than those for the PPDL homopolyester when they are referred to the weight fraction of PDL in the copolymer. It seems therefore that the PEG segment operates as a crystallization hastener probably due to self-assembling effect that is exerted on the whole copolymer in concomitance with phase separation. Additionally a plasticizing effect of PEG could be invoked to explain the high crystallinity found in these copolymers. Crystallization upon cooling from the melt was found to take place in all cases at supercoolings below $10 \stackrel{\circ}{\circ}$ which are values significantly lower than that required for the recrystallization of the homopolyester $\left(16^{\circ} \mathrm{C}\right)$.
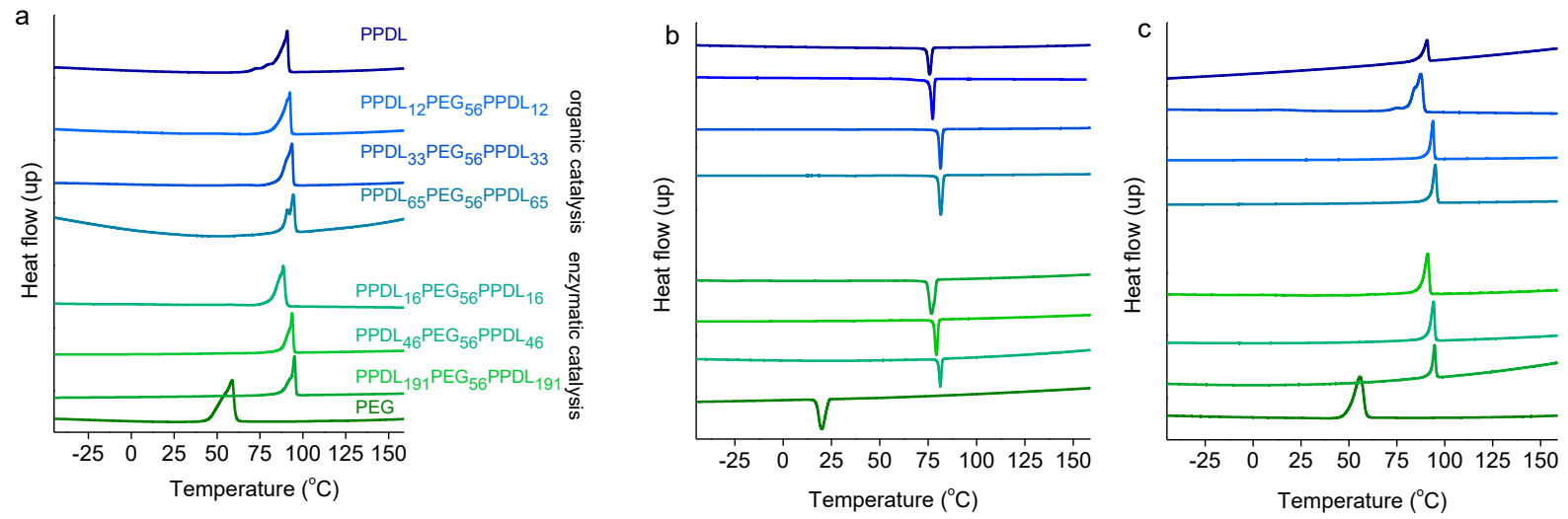

Fig. 5. DSC traces of $P P D L_{x} P E G_{56} P P D L_{x}$ copolymers. a) First heating, b) cooling, c) second heating. 
The crystallizability of the copolymers as a function of their composition was assessed by isothermal crystallization. For this purpose PPDL and copolymers samples were heated in the DSC up to $200^{\circ} \mathrm{C}$, then rapidly cooled down to $84^{\circ} \mathrm{C}$, and finally left to crystallize at this temperature. The advance of the crystallization process was followed by measuring the increasing in the enthalpy along time. The curves resulting from the representation of the relative crystallinity against crystallization time are compared in Fig. 6 for the two series and the kinetic parameters determined by applying the Avrami approach for each copolymer and PPDL are listed in Table 3. It is apparent that the PPDL segments crystallized faster when they were dangling from the PEG, and that such effect is even more pronounced in the copolymers synthesized in the presence of the organic catalyst than in those obtained with CALB. The POM micrographs obtained from films of copolyesters crystallized under the same conditions that were used for the kinetic analysis (insets of Fig. 6) revealed an axialite-like texture in both cases but with bigger size and less profusion of individual entities in the former case. These findings are in line with the differences detected in the melting-crystallization and corroborated the occurrence of heterogeneous crystallization in the TBD synthesized copolymer. Avrami parameters are in partial agreement with such observations. Half crystallization times are in fact much lower for the organo-catalyzed copolymers whereas no significant differences in $n$ between the two series where noticed.

The crystalline structure generated upon crystallization of $P P D L_{x} P E G_{56} P P D L_{x}$ was investigated by $\mathrm{XRD}$ at variable temperature by using synchrotron radiation. All the copolymers showed at room temperature a couple of well-resolved sharp peaks in the WAXS region corresponding to 0.41 and $0.37 \mathrm{~nm}$ Bragg spacings (Fig. 7). These are identified as the interplanar spacings characteristic of the PPDL rhombic lattice, [3,32-34] 

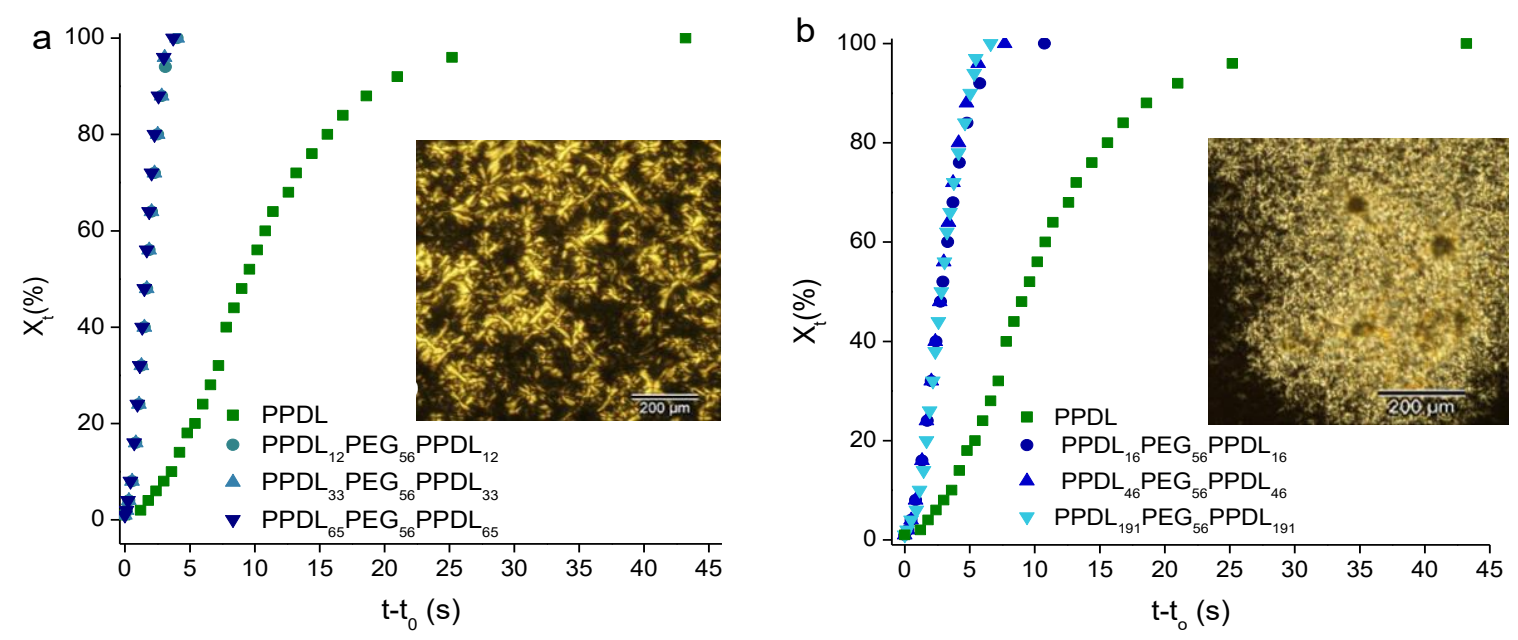

Fig. 6. Evolution of the relative crystallinity as a function of time in the isothermal crystallization at $84{ }^{\circ} \mathrm{C}$ of $\mathrm{PPDL}_{\mathrm{x}} \mathrm{PEG}_{56} \mathrm{PPDL}_{\mathrm{x}}$ copolymers. Insets: POM micrographs recorded from crystallized $\mathrm{PPDL}_{33} \mathrm{PEG}_{56} \mathrm{PPD}_{33}$ (a) and PPDL ${ }_{46} \mathrm{PEG}_{56} \mathrm{PPDL}_{46}$ (b).

and their presence brings into evidence that the PPDL segments are similarly crystallized in the copolyesters whichever is their composition. As expected, both peaks vanished when the copolymers were heated at their melting temperature to reappear upon cooling to reproduce almost exactly the initial pattern. According to the results obtained by DSC, the amount of PEG that is crystallized must be small. In fact no peak arising from PEG was detectable in the XRD profiles of the copolymers except in those containing the shortest PPDL blocks. In these cases a weak peak became detectable at $0.46 \mathrm{~nm}$ that disappeared at temperatures around $50-60{ }^{\circ} \mathrm{C}$ and that was unable to recover upon cooling (Fig. 7c).

a

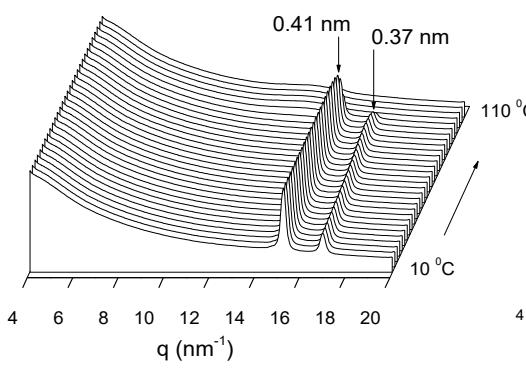

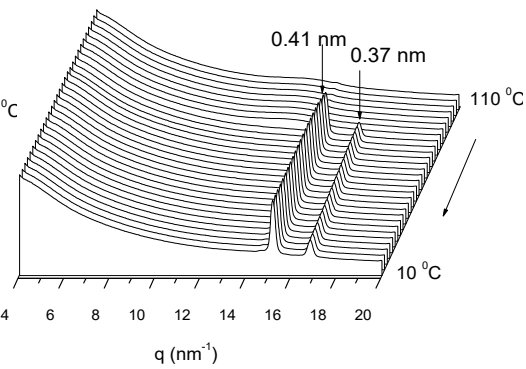

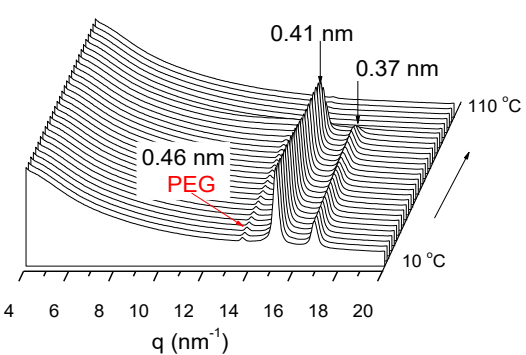

Fig. 7. Evolution of WAXS recorded from $P P D L_{46} \mathrm{PEG}_{56} \mathrm{PPDL}_{46}$ at heating (a) and cooling (b) over the $10-110{ }^{\circ} \mathrm{C}$ range. c) WAXS profiles recorded from $P P D L_{16} P E G_{56} P P D L_{16}$ showing the PEG peak. Additional heating and cooling profile collections obtained for $P P D L_{191} P E G_{56} P P D L_{191}$ are given in Fig. S7 of the ESI file. 


\subsection{Nanoparticles formation and characterization}

The PPDL ${ }_{x} P E G_{56} P P D L_{x}$ triblock copolymers are amphiphilic chains consisting of an inner hydrophilic segment of around $20 \mathrm{~nm}$ in length and two outer hydrophobic segments of variable length ranging from about $25 \mathrm{~nm}$ for $\mathrm{x}=12$ up to about $400 \mathrm{~nm}$ for $\mathrm{x}$ $=191$. Since the PEG segment in the solid state is likely to be in non-regular conformation, and that PPDL must be crystallized in folded lamellae with a more or less defined thickness (presumably in the $5-30 \mathrm{~nm}$ range), the copolymers are expected to be arranged in an amphiphilic nanostructure with the PEG (amorphous and hydrophilic) and PPDL (crystalline and hydrophobic) phases sharply segregated one from the other. Since no peak was detected in the SAXS region of the XRD profiles recorded from these copolymers it is interpreted that such structure is made of globular PEG amorphous aggregates surrounded by a continuous phase of semicrystalline PPDL. The size and mutual distribution of the two phases will be determined by the $x$ value.

A different behavior could be however expected for the copolymers when they are compelled to form small particles in an aqueous environment given the strong affinity of PEG for water. The preparation of nanoparticles (NPs) from the $P P D L_{x} P E G_{56} P P D L_{x}$ copolyesters was carried out by the solvent evaporation method with dichloromethane as organic solvent. The copolymer series made by enzymatic copolymerization was the material of choice because a greener synthesis route was used in this case. The size and $\zeta$-potential measured for the resulting NPs for the three copolymers under study are given in Table 4, and a selected assortment of TEM micrographs are shown in Fig. 8. 
Table 4. Triblock $P P D L_{x} P E G_{56} P P D L_{x}$ nanoparticles characteristics.

\begin{tabular}{|c|c|c|c|}
\hline \multirow[b]{2}{*}{ Copolymer } & \multicolumn{2}{|c|}{ Particle size $^{a}$} & \multirow[b]{2}{*}{$\zeta$-potential (mV } \\
\hline & diameter $(\mathrm{nm})$ & dispersity $(D)$ & \\
\hline $\mathrm{PPDL}_{16} \mathrm{PEG}_{56} \mathrm{PPDL}_{16}$ & 125 & 0.12 & -3.33 \\
\hline $\mathrm{PPDL}_{46} \mathrm{PEG}_{56} \mathrm{PPDL}_{46}$ & 165 & 0.19 & -3.90 \\
\hline $\mathrm{PPDL}_{191} \mathrm{PEG}_{56} \mathrm{PPDL}_{191}$ & 161 & 0.13 & -2.96 \\
\hline
\end{tabular}

${ }^{a}$ Measured by DLS in water. Size distribution plots are accessible in the ESI file (Fig. S8).

The DLS results gave particle sizes between 125 and $160 \mathrm{~nm}$ with the value clearly increasing when the length of the PPDL block came from $x=16$ up to $x=46$ but keeping essentially unchanged for further increasing of the $X$ value to 191 . Negative weak values were found for the $\zeta$-potential, as it should be expected for particles with the surface enriched in ethylene oxide groups. Differences among $\zeta$-potential are not relevant although it is rather remarkable that $P P D L_{46} P G_{56} P_{P D L}$ displays the top value despite that $\mathrm{PPDL}_{16} \mathrm{PEG}_{56} \mathrm{PPDL}_{16}$ is the copolyester containing the highest proportion of ether groups. The entities examined by SEM display sizes and shapes in agreement with the data afforded by DLS. Although more or less rounded particles with diameters in the 100-200 $\mathrm{nm}$ range are invariably observed for the three copolymers, their appearance varies largely from one to the other. NP's made of $\mathrm{PPDL}_{16} \mathrm{PEG}_{56} \mathrm{PPDL}_{16}$ are very prone to collapse and aggregate so that patches integrated by large numbers of attached NP are frequently seen (Fig. 8a). On the contrary, NP's made of $P P D L_{191} P E G_{56} P P D L_{191}$ appear very disperse maintaining their individual entity and displaying somewhat elongate shapes (Fig. 8c). An intermediate situation was found for NP's made of $P P D L_{46} P G_{56} P P D L_{46}$ where rounded particles appear densely packed without losing their individuality. Additional SEM micrographs providing larger views of the $\mathrm{PPD}_{x} \mathrm{PEG}_{56} \mathrm{PPDL}_{x}$ NP's may be inspected in Fig. S9 of the ESI file. 

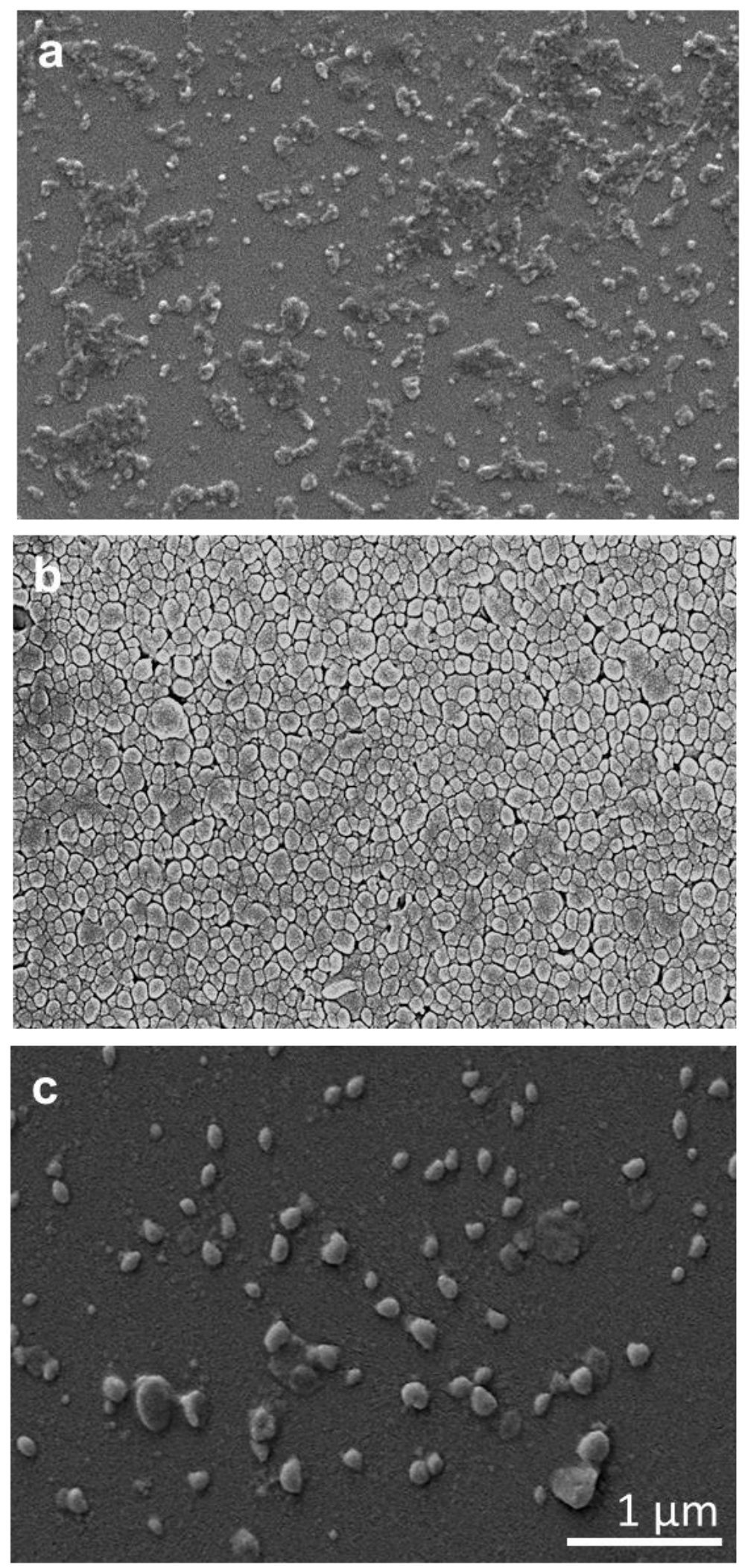

Fig. 8. SEM images of nanoparticles made from $P P D L_{16} P G_{56} P P D L_{16}(a), P P D L_{46} P G_{56} P P D L_{46}$ (b) and $\mathrm{PPDL}_{191} \mathrm{PEG}_{56} \mathrm{PPDL}_{191}(\mathrm{c})$ triblock copolymers. 
The DSC analysis of the NP's demonstrated that the polyester blocks are crystallized in these entities in a similar manner as it happens in the powder but the crystallinity attained is much lower depending on copolymer composition (see Fig. S10 and Table S1 of the ESI file). On the other hand, no sign of crystallinity associated to the PEG blocks is perceived at any case. It is remarkable that the amount of crystalline PPDL in the NPs made of $\mathrm{PPDL}_{46} \mathrm{PEG}_{56} \mathrm{PPDL}_{46}$ is about $80 \%$ of that present in the copolymer in powder whereas it becomes less than $7 \%$ in NPs made of $P P D L_{16} P E G_{56} P P D L_{16}$. The situation is intermediate for $\mathrm{PPDL}_{191} \mathrm{PEG}_{56} \mathrm{PPDL}_{191}$ NPs where PPDL crystallized in about $25 \%$ relative to the amount that is crystallized in the powder.

It is tempting to try relating the differences in shape and behavior exhibited by the NP's in aqueous suspension with the composition of the copolymers given the influence of the block length on crystallinity and the low $T_{g}$ values displayed by both PEG and PPDL. The soft behavior and consequent low shape definition and tendency to form unspecific aggregates that is displayed by $\mathrm{PPDL}_{16} \mathrm{PEG}_{56} \mathrm{PPDL}_{16} \mathrm{NPs}$ is thought to be due to the rubbery nature of these particles in which the molar fraction of EG units is almost twofold that of PDL and crystallinity is almost negligible. Conversely the good dispersion and almond-like shape exhibited by $\mathrm{PPDL}_{191} \mathrm{PEG}_{56} \mathrm{PPDL}_{191} \mathrm{NPS}$ is consistent with the presence of a considerable crystallinity and small content in PEG, which will be segregated out from the polyester core, as expected, but that is insufficient to cover the whole surface of the nanoparticle. NPs made of $P P D L_{46} P E G_{56} P P D L_{46}$, despite showing a good mutual affinity, they keep inalterable their identity and display a satisfactory rounded shape. In this case, PPDL is extensively crystallized in the inner part of the NP so that PEG is segregated out to create an homogeneus water-like surface. Nevertheless, the amorphous polymer fraction in these NP must be considerable as it inferred from the polygonal contour exhibited when they are closely packed to each other. 


\section{Conclusions}

In this paper it is reported for the first time the synthesis of polymacrolactones by ROP using amino-initiators and avoiding the concourse of organo-metallic catalysts. This approach is very suitable to prepare telechelic PE-like polyesters bearing diverse functional-end groups which can be then used for further extensive reaction. In this work, the methodology has been applied to the preparation of amphiphilic triblock copolyesters (PPDL-PEG-PPDL) made of a central block of PEG and two dangling blocks of PPDL. Copolymerization was performed by ROP of PDL initiated by amino-ended PEG and using either TBD or CALB catalysis with similar synthesis results. The length of the polyester blocks could be precisely controlled by adjusting the PEG/PDL ratio. Thermal properties and crystalline structure of the copolymers were found to be depending on the PEG/PDL ratio but differences between the two copolymer series were not significant. Strikingly the crystallizability of the PPDL in the copolymers was enhanced compared to that of the homopolyester and this effect was more pronounced for the copolymer series prepared with TBD as catalyst. Nanoparticles with 100-200 nm diameter could be prepared from the enzymatically-synthesized copolyesters bringing into evidence their self-assembling capacity. The green route followed for the preparation of the PPDL-PEG-PPDL triblock copolyesters, their largely expected biodegradability and good cytocompatibility, and their capacity to form structured nanoparticles make these copolyesters materials of exceptional interest for the design of drug delivery systems.

\section{Acknowledgements}

Financial support for this research was afforded by MINECO with grants MAT-201677345-CO3-01 and MAT-2016-77345-CO3-02. Funding and beam-time provided by ALBA synchrotron facility is acknowledged. E. Tinajero-Díaz thanks CONACYT (México) for the 
Ph.D. grant and to L'Obra Social la Caixa (Spain) for the Beca de Mobilitat Internacional in 2016. Authors are indebted to Dr. Ana Gamarra for her assistance with XRD experiments.

\section{Supporting Information}

${ }^{1} \mathrm{H}$ NMR of polymers and copolymers showing end-group and composition analysis details; WAX profiles of copolymers recorded at real time and variable temperature; SEM micrographs of copolymer nanoparticles; DLS plots of copolymer nanoparticles; DSC of nanoparticles and Table containing compared DSC data of copolyesters as powder and as nanoparticles.

\section{Data Availability}

The raw/processed data required to reproduce these findings cannot be shared at this time due to time limitations.

\section{References}

[1] K.M. Zia, A. Noreen, M. Zuber, S. Tabasum, M. Mujahid, Recent developments and future prospects on bio-based polyesters derived from renewable resources: A review, Int. J. Biol. Macromol. 82 (2016) 1028-1040.

[2] P. Hodge, Entropically driven ring-opening polymerization of strainless organic macrocycles, Chem. Rev. 114 (2014) 2278-2312.

[3] M.L. Focarete, M. Scandola, A. Kumar, R. A. Gross, Physical Characterization of poly ( $\omega$-pentadecalactone) Synthesized by lipase-catalyzed ring-opening polymerization, J. Polym. Sci. Part B, Polym. Phys. 39 (2001) 1721-1729.

[4] Y. Li, X. Yin, M. Dai, Catalytic macrolactonizations for natural product synthesis, Nat. Prod. Rep. 34 (2017) 1185-1192. 
[5] C. Thomas, B. Bibal, Hydrogen-bonding organocatalysts for ring-opening polymerization, Green Chem. 16 (2014) 1687-1699.

[6] M. Takwa, N. Simpson, E. Mcilmsitröm, K. Hult, M. Martinelle, One-pot difunctionalization of poly(w-pentadecalactone) with thiol-thiol or thiol-acrylate groups catalyzed by candida antarctica lipase B, Macromol. Rapid Commun. 27 (2006) 1932-1936.

[7] M. Bouyahyi, M.P.F. Pepels, A. Heise, R. Duchateau, w-Pentandecalactone polymerization and $\omega$-pentadecalactone/ $\varepsilon$-caprolactone copolymerization reactions using organic catalysts, Macromolecules 45 (2012) 3356-3366.

[8] T. Fuoco, D. Pappalardo, Aluminum alkyl complexes bearing salicylaldiminato ligands: Versatile initiators in the ring-opening polymerization of cyclic esters, catalysts. 7 (2017) 64.

[9] A.E. Polloni, V. Chiaradia, E.M. Figura, J.P. de Paoli, D. de Oliveira, J.V. de Oliveira, P.H.H. de Araujo, C. Sayer, Polyesters from macrolactones using commercial lipase ns 88011 and Novozym 435 as biocatalysts, Appl. Biochem. Biotechnol. (2017) 1-14.

[10] L. Mezzasalma, A.P. Dove, O. Coulembier, Organocatalytic ring-opening polymerization of L-lactide in bulk: A long standing challenge, Eur. Polym. J. 95 (2017) 628-634.

[11] L. Simón, J.M. Goodman, The mechanism of TBD-catalyzed ring-opening polymerization of cyclic esters, J. Org. Chem. 72 (2007) 9656-9662.

[12] R.C. Pratt, B.G.G. Lohmeijer, D.A. Long, R.M. Waymouth, J.L. Hedrick, Triazabicyclodecene : a simple bifunctional organocatalyst for acyl transfer and ringopening polymerization of cyclic esters, J. Am. Chem. Soc. 128 (2006) 4556-4557.

[13] A. Duda, A. Kowalski, S. Penczek, H. Uyama, S. Kobayashi, Kinetics of the ringopening polymerization of 6-, 7-, 9-, 12-, 13-, 16-, and 17-membered lactones. 
Comparison of chemical and enzymatic polymerizations, Macromolecules 35 (2002) $4266-4270$.

[14] J.C. Chen, J.Z. Li, J.H. Liu, L.Q. Xu, Amphiphilic poly(ethylene glycol)-bpoly(ethylene brassylate) copolymers: One-pot synthesis, self-assembly, and controlled drug release, Chinese Chem. Lett. 26 (2015) 1319-1321.

[15] C.-M. Dong, K.-Y. Qiu, Z.-W. Gu, X.-D. Feng, Synthesis of star-shaped poly(Ecaprolactone)-b-poly(dl-lactic acid-alt-glycolic acid) with multifunctional initiator and stannous octoate catalyst, Macromolecules 34 (2001) 4691-4696.

[16] V. Ladelta, P. Bilalis, Y. Gnanou, N. Hadjichristidis, Ring-opening polymerization of $\omega$-pentadecalactone catalyzed by phosphazene superbases, Polym. Chem. 8 (2017) 511-515.

[17] M. Yuan, Y. Wang, X. Li, C. Xiong, X. Deng, Polymerization of lactides and lactones. 10. Synthesis, characterization, and application of amino-terminated

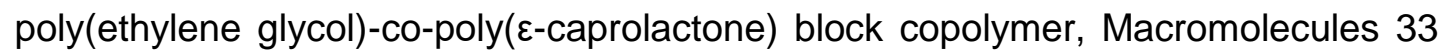
(2000) 1613-1617.

[18] M. Marzorati, K. Hult, S. Riva, B. Danieli, Incorporation of primary amines into a polyester chain by a combination of chemical and lipase-catalyzed $\varepsilon$-caprolactone ring-opening processes, Adv. Synth. Catal. 349 (2007) 1963-1968.

[19] M. Bednarek, M. Basko, T. Biedron, E. Wojtczak, A. Michalski, Polymerization of lactide initiated by primary amines and catalyzed by a protic acid, Eur. Polym. J. 71 (2015) 380-388.

[20] T. Biela, A. Kowalski, J.A.N. Libiszowski, Amines as (co) initiators of cyclic esters polymerization, Polymery, 7-8, (2005) 501-504.

[21] J. Liu, L. Liu, Ring-opening polymerization of $\varepsilon$-caprolactone initiated by natural amino acids, Macromolecules 37 (2004) 2674-2676. doi:10.1021/ma0348066.

[22] [Y. Tsukahara, K. Adachi, Telechelic polymers: preparation and application, in: S. 
Kobayashi, K.Müllen (Eds.), Encyclopedia Polymeric Nanomaterials, Springer, Berlin, Heidelberg, 2014, pp. 1-8.

[23] M. de Geus, R. Peters, C.E. Koning, A. Heise, Insights into the initiation process of enzymatic ring-opening polymerization from monofunctional alcohols using liquid chromatography under critical conditions, Biomacromolecules 9 (2008) 752-757.

[24] X.W. Wei, C.Y. Gong, M.L. Gou, S.Z. Fu, Q.F. Guo, S. Shi, F. Luo, G. Guo, L.Y. Qiu, Z.Y. Qian, Biodegradable poly(ع-caprolactone)-poly(ethylene glycol) copolymers as drug delivery system, Int. J. Pharm. 381 (2009) 1-18.

[25] L.S. Nair, C.T. Laurencin, Biodegradable polymers as biomaterials, Prog. Polym. Sci. 32 (2007) 762-798.

[26] M. Sobczak, Enzyme-catalyzed ring-opening polymerization of cyclic esters in the presence of poly(ethylene glycol), J. Appl. Polym. Sci. 125 (2012) 3602-3609.

[27] H. Ge, Y. Hu, X. Jiang, D. Cheng, Y. Yuan, H. Bi, C. Yang, Preparation, characterization, and drug release behaviors of drug nimodipine-loaded poly(epsilon-caprolactone)-poly(ethyleneoxide)-poly(epsilon-caprolactone) amphiphilic triblock copolymer micelles., J. Pharm. Sci. 91 (2002) 1463-1473.

[28] C. Chen, C.H. Yu, Y.C. Cheng, P.H.F. Yu, M.K. Cheung, Biodegradable nanoparticles of amphiphilic triblock copolymers based on poly(3-hydroxybutyrate) and poly(ethylene glycol) as drug carriers, Biomaterials 27 (2006) 4804-4814.

[29] J. Lee, E.C. Cho, K. Cho, Incorporation and release behavior of hydrophobic drug in functionalized poly(D,L-lactide)-block-poly(ethylene oxide) micelles, J. Control. Release. 94 (2004) 323-335.

[30] O. Nuyken, S.D. Pask, Ring-opening polymerization. An introductory review, Polymers (Basel). 5 (2013) 361-403.

[31] E. Calahorra, M. Cortazar, G.M. Guzman, Thermal decomposition of poly(ethylene oxide), poly(methyl methacrylate), and their mixtures by thermogravimetric method., 
J. Polym. Sci. Polym. Lett. Ed. 23 (1985) 257-260.

[32] L. Mazzocchetti, M. Scandola, Z. Jiang, Copolymers of ethyl glycolate and $\omega$ pentadecalactone: Enzymatic synthesis and solid-state characterization, Eur. Polym. J. 47 (2011) 942-948.

[33] J. Fernández, A. Etxeberria, J.-R. Sarasua, Synthesis and properties of $\omega$ pentadecalactone-co- $\delta$-hexalactone copolymers: a biodegradable thermoplastic elastomer as an alternative to poly( $\varepsilon$-caprolactone), RSC Adv. 6 (2016) 3137-3149.

[34] Z. Jiang, H. Azim, R.A. Gross, M.L. Focarete, M. Scandola, Lipase-catalyzed copolymerization of $\omega$-pentadecalactone with $p$-dioxanone and characterization of copolymer thermal and crystalline properties, Biomacromolecules 8 (2007) 22622269. 